\title{
Sobre el origen y significado del nombre de Extremadura. Estudio historiográfico de la etimología duriense
}

\author{
Bonifacio Palacios Martín *
}

Comenzamos con este trabajo un estudio histórico-lingüistico sobre el origen y significado del nombre de Extremadura. Es nuestro propósito analizar sistemáticamente las variantes terminólogicas que se emplean, así como la relación que desde una perspectiva histórica guardan entre si. Pero sobre todo trataremos de fijar los diferentes significados que tales términos fueron adquiriendo con el correr de los tiempos.

El interés del tema radica tanto en la riqueza de matices y de situaciones que se ocultan bajo esas variantes lexicográficas como en la amplitud espacial de su empleo. Pues, aunque en un determinado momento cierto sector historiográfico vinculó esta temática - sobretodo la del origen del nombre - a la Extremadura actual, es claro que se trataba de un planteamiento reduccionista, que ignoraba el dato fundamental de que las «Extremaduras» fueron un hecho común a todos los reinos y territorios hispánicos de la reconquista, y que todos ellos usaron términos similares como extremo, extremadura, estremadoiro, estrems, etc., para significarlas, tal como aparece reflejado en la documentación y en la toponimia.

No obstante, debo advertir que este estudio se va a limitar a las extremaduras castellanoleonesas, y que sólo serán tenidas en cuenta las demás cuando resulte imprescindible para el buen entendimiento de los procesos que hayamos de analizar.

Conviene también tomar conciencia desde ahora de la extraordinaria complejidad del tema. A la amplitud espacial a que antes haciamos refe-

\footnotetext{
* Universidad Complutense.
} 
rencia hay que añadir la amplitud cronológica de los fenómenos que vamos a analizar, que se suceden a lo largo de varios siglos desde la Alta Edad Media hasta bien entrada la Moderna. Pero sobre todo influye la naturaleza de las realidades histórico-geográficas. El concepto de Extremadura nace ligado al de frontera: al de la frontera de los reinos cristianos de la reconquista, que a partir del siglo $x$ entran en una fase expansiva, lo que hará que aquella cobre una extraordinaria movilidad. Habiendo alcanzado en esta centuria las riberas del Duero, se situará en la siguiente en el Sistema Central, saltando luego al sur de la Sierra para colocarse sucesivamente en el Tajo y Guadiana, penetrando inmediatamente en Andalucía. Todos estos factores influyen en el doble proceso, lexicográfico y semántico, que con extraordinaria intensidad, producen la renovación de la terminología empleada así como la modificación de sus significados, ya sea por la incorporación de nuevos matices, ya por la variación de los territorios a los que se aplican.

Esas variaciones harán que tales regiones y territorios se encuentren en posiciones geográficas diferentes según las épocas, lo que induce a sus habitantes a entender el nombre de Extremadura de acuerdo con la que ocupan en ese momento, lo que produce a veces visiones distorsionadas del mismo. Pero en este proceso distorsionador correspondió también un papel importante a la historiografía en su condicción de vehículo transmisor de conocimientos y estados de opinión de las diferentes épocas. En efecto vamos a comprobar cómo en más de una ocasión se vió condicionada por las dificultades mencionadas, a más de otras limitaciones de perspectiva histórica o de información. De esta manera se convierte en un factor más a tener en cuenta a la hora de analizar el origen y los significados del nombre de Extremadura.

Por todo lo cual parece oportuno comenzar su estudio por una revisión historiográfica del tema. La premura de tiempo, impuesta por mi deseo de participar en este homenaje a la labor docente e investigadora del Prof. Benito Ruano, me obliga a circunscribirme, por ahora, a una única cuestión: la interpretación etimológica que hace derivar el nombre de Extremadura de los «Extrema Dorii". Sin entrar a valorar si es o no correcta, una cuestión previa se nos plantea: dónde, cómo y cuándo surge esa teoría. 


\section{LA ÉPOCA MEDIEVAL}

Un trabajo reciente del prof. G. Martínez Díez atribuye la famosa etimología a un grupo de notarios leoneses de finales del siglo $\mathrm{XII}^{1}$. Según este autor, los notarios habrían tomado partido por esa interpretación etimológica al incluir en la data crónica de sus documentos la expresión «Extrema Dorii» en fórmulas como la de «regnante... in legione, Gallecia, Asturias, "Extremis Dorii" o similares, que localiza por primera vez en 1181 en un documento del monasterio, de San Martín de Castañeda, en la sanabria Zamorana, reiterándose en los años siguientes en diplomas de ese monasterio y en otros dos documentos, uno de la catedral salmantina y otro de la Cancillería real de 1189 y 1193 respectivamente ${ }^{2}$. Esta interpretación de cel vocablo Extremadura como Extrema Dorii o los Extremos del Duero» es calificada por el autor de «artificioso culturismo de finales del siglo XII» "totalmente insostenible» a poco que se examine la documentación medieval. La interpretación del nombre de Extremadura -continùa diciendo- como derivado de «extrema Dorii» por otra parte, había sido ya popularizada en el siglo XIII por don Rodrígo Jiménez de Rada que reiteradamente, al menos hasta diez veces, habla de los Extremos del Duero y tres de ellas contraponiendo estos Extremos del Duero a Castilla ${ }^{3}$.

Se nos indica, por tanto aquí no sólo el origen sino también el camino de divulgación de una explicación del nombre de Extremadura que iba a disfrutar de gran aceptación en la historiografía posterior hasta alcanzar a nuestros días, en los que sigue figurando en importante trabajos de investigación, contra lo que Martínez Diez reacciona enérgicamente. Como decíamos antes, no vamos a entrar por ahora, a valorar esa interpretación etimológica. Lo que nos interesa es saber si es realmente atribuible a los notarios mencionados, ya intencionada o inintencionadamente.

Comenzamos por ofrecer una descripción algo más completa del hecho documental señalado, es decir, de la utilización de la expresión: «Ex-

1 G. Martinez Diez: Origen del nombre de Extremadura. Badajoz. Publicado anteriormente con el título de Extremadura, origen del nombre y formación de las dos provincias. "anuarios de la Facultad de Derecho. Universidad de Extremadura" 2(1983) 82-104, 1985.

${ }^{2}$ Ibid., págs. 22-32.

${ }^{3}$ Ibid., págs. 15-16. 
trema Dorii» en los documentos. En el año 1181 la reproduce además del documento citado por Martínez Díez, otro diploma redactado no muy lejos del anterior, perteneciente a la catedral zamorana ${ }^{4}$, mientras que en el cartulario sanabrés se repite otras quince veces entre $1181 \mathrm{y}$ $1222^{5}$. En el primero de ellos, citado por Martínez Díez, aparece además la mención del notario, Nuño, del recién creado concejo de Benavente ${ }^{6}$. El dato es importante porque no lejos de esta población vamos a encontrar poco tiempo después otro centro monástico, Santa Maria de Moreruela, que emplea también en sus documentos entre 1207 y 1218 la expresión «Extrema Dorii» alrededor de media docena de veces, la mayoría de ellas en asuntos relacionados con Villalobos de Lenguar, lugar situado a menos de cinco leguas de Benavente, y todos ellos firmados por un mismo notario, lohannes ${ }^{?}$.

El posible que el número de casos en los que se emplea la expresión «Extrema Dorii» pudiera incrementarse. la misma cancillería leonesa la utiliza, además de la citada por Martínez Díez, en otras cuatro ocasiones entre 1193 y $1195^{\circ}$. Pero será difícil que nuevos hallazgos modifiquen la impresión de que estamos ante un uso originado y casi limitado al territorio comprendido dentro del triángulo formado por Zamora, Sanabria y Benavente, con posible protagonismo de los notarios de esta última. Se trata, en definitiva, de la zona leonesa que a esa altura del Duero se recuesta sobre su margen derecha, detalle éste que - junto con otros datos- puede sernos de gran ayuda a la hora de indagar el sentido que los notarios quieren darle a esa expresión y por qué aparece ahi y no en otros lugares.

En efecto, conocida el área de difusión de la misma, procede preguntar cuál es el sentido de la locución "Extrema dorii" y qué circunstan-

4 "Regnante rege Fernando cum filio suo Alfonso in Legione, Gallecia, Asturiis et in Extremis Dorii". J.L. MARTiN, Documentos zamoranos. I. Documentos del archivo catedralicio de Zamora. primera parte (1.128-1.261). Salamanca, 1982, pág. 34, doc. 31.

5 A. Rodriguez Gonzalez: El tumbo del monasterio de San Martín de Castañeda. León, 1973, págs. 117, 122, 143, 147, 149,156,160,162, 165, 168, 171, 181, 233 y 238.

6 "Nunus, notarius concilii Beneventi scripsit el confirma". El nombre de Nuño aparece, junto al de otros escribas, empleando unas veces la forma Extremadura y otras la de Extrema Dorii. Ibid., pág. 117.

7 M. Luisa Bueno Dominguez: El monasterio de Santa María de Moreruela (1143-1300). Zamora, 1975, págs. 163, 165, 171 y 174. En uno de 1218, págs. 180-181, se usa esta fórmula singular: «regnante rege Aldefonso in Legione, Gallecia, Asturiis, Strematura et in partibus Dorii».

8 Julio Gonzalez: Alfonso IX, II, Madrid, 1944, págs. 97, 98, 113, 132 y 139. 
cias indujeron a emplearla. Nuestra respuesta es que en la utilización de la misma por los notarios zamoranos no observamos preocupación filológica alguna que permita atribuirles la famosa etimología de la palabra Extremadura. Lo único que hacen es proseguir en el empleo de otro término «Extremo», de origen anterior al de Extremadura, aunque algo desplazado últimamente por la irrupción arrolladora de esta última palabra. Y lo hacen para distinguir, con la ayuda de la especificación topográfica "del Duero", una realidad nueva que se ha venido desarrollando entre ese río y el Sistema Central. Trataremos de demostrar todo esto lo más brevemente posible.

Lo primero que se observa es que los notarios no funden la expresión en una sola palabra sino que ambas aparecen separadas y declinables: "Extrema Dorii», "in Extremis Dorii», sin que se atisbe ningun intento de conformar con ella ningún neologismo ni mucho menos desentrañar la etimología de la palabra Extremadura ${ }^{9}$. Tampoco aparece ningun intento similar en el empleo que hace Jimenez de Rada, que usa los términos también declinables y separados, aplicándola generalmente a Castilla pero también en algún caso a León. Para unos y otros Extremo y Extremadura son intercambiables. Nadie entiende que la segunda palabra esté formada por la suma de Extremo y Duero. Así, por ejemplo, cuando la Primera Crónica General refunde los pasajes de Jiménez de Rada en los que éste usa la locución «Extrema Dorii» sustituyendola por Extremadura, nos hablará de «las Extremaduras de duero» o «las Extremaduras de allend duero" o "la Extremadura del regno de Leon que yace allend de Duero" ${ }^{10}$, lo que sería una redundancia si hubiesen entendido que la palabra «Duero» estaba incluida en «Extremadura».

Creemos, pues, que los notarios zamoranos hacen proseguir en la utilización de la voz "extremo», añadiéndole una precisión topográfica. Hablamos de proseguir, no de innovar, ya que existía una larga tradición en el uso de la misma, últimamente complicada por la aparición de realidades y expresiones terminológicas nuevas, de las que la propia expresión "extremos del Duero" es una muestra más. No es este el momento

- No parece que sea óbice a esta conclusión el hecho de que en tres de los cinco documentos reales que la emplean, las dos palabras parezcan unidas: Extremadorii: $\mathbf{I}$. GonzÁlez, Alfonso IX, II, pp. 97, 98, 132, 113 y 139 respectivamente. Se trata de casos aislados, alejados del lugar donde el fenómeno se produce, y en los que no hay que excluir la posibilidad de un lapsus del copista.

10 Primera Crónica General, ed. R. MEnÉndez PIDAL. Madrid, Gredos, 1977, págs. 423b, $669 \mathrm{~b}$ y $711 \mathrm{a}$. 
de describir todo el proceso lexicográfico que se está produciendo. Pero sí se hace necesaria una breve síntesis del mismo para situar dentro de él la innovación de los notarios zamoranos.

El núcleo inicial del proceso lo constituye la palabra extremus, ya adjetivada acompañando a algún sustantivo ("extremas partes» "extremis locis»), ya sustantivada en latín o romance ${ }^{11}$. En la segunda mitad del siglo XI aparece documentado por primera vez el término Extremadura ${ }^{12}$, seguramente por la necesidad de atender a los nuevos significados, pues para entonces ya designaba probablemente a una región geográfica concreta. Era una derivación vulgar, que habría de tener un éxito popular muy grande, aunque en determinados niveles cultos encontró algunas resistencias. Los eclesiásticos compostelanos lanzaron como equivalente el término Extremitas, que aparece por primera vez, en las actas del Concilio de Compostela de $1.114^{13}$, y reiteradamente en la Historia Compostelana ${ }^{14}$.

Así pues de que en 1181 apareciera documentada la expresión «Extrema Dorii», se había producido ya una cierta riqueza de formas terminológicas, aunque con diferente fortuna. La de la forma culta Extemitas concluyó practicamente con el primer libro de la Compostelana. La de Extrematura o Extremadura - ambas modalidades se usan en latín, y la segunda además en romance- no paró, en cambio, de crecer hasta convertirse en la dominante en crónicas y documentos ${ }^{15}$. En cuanto a la voz «Extremo» retrocedió sin duda ante la competencia de los otros términos, especialmente de Extremadura, pero tampoco desapareció del ho-

"Pueden verse ejemplos en A.C. Floriano Cumbreño: Estudios de Historia de Cáceres. I. De los origenes a la Reconquista. Oviedo, 1957, págs. 90-91; G. MARTínez Díez, Origen del nombre, p. 16 y ss; R. Menéndez PIDAL, La Expaña del Cid, II, Madrid, 19, págs. 933-934.

12 G. MARTinez Díez: Origen del nombre, págs. 16-17.

13 A. López Ferreiro: Historia de ia Santa A.M. Iglesia de Santiago de Compostela., 1902, Vol. III, apénd. 31.

${ }_{14}$ España Sagrada, XX, págs. 130, 150, 155, 163, 192, 211 y 250: tras emplear una vez la palabra Extremo (cap. 73), utiliza luego otras seis la forma Extremitas entre los capítulos 88 y 117, todos del libro I, y una sola vez la forma Extrematura (cap. 84). Es de notar que, según la opinión mayoritaria de quienes se han ocupado del autor de la Compostelana, los capitulos en que aparecen esas expresiones pertenecen en su práctica totalídad a Giraldo, de origen francés. L. VONES, Die "Historia Compostelana" und die Kirchenpolitik des Nordwestspanischen Raumes, 1070-1130. Köln-Wien, 1980, pág. 67.

${ }^{15}$ La emplea el obispo Pelayo de Oviedo en su Chronica Regum Legionensium. Cfr. España Sagrada, XIV, pág. 488. Su presencia en documentos reales y privados desde la segunda década del siglo XII, ver G. MARTínez DíEz, El nombre de Extremadura, 16 y ss. 
rizonte linguístico y cultural que alcanzaban los notarios zamoranos. Sirva de ejemplo cualificado la Chronica Adefonsi Imperatoris, posiblemente la fuente que mejor refleja la evolución de los gustos en este tema. En efecto, tras emplear al principio y por una sola vez la forma culta Extremitas en una conocida frase, cuyo eco parece resonar en los notarios zamoranos ${ }^{16}$, utilizará a continuación a lo largo del libro I la forma «Extremo» de modo preferente: cuatro veces frente a una la de Extremaduta; mientras que a partir del libro II es esta última la única que aparece ${ }^{17}$. También el Poema de Almería, como antes la Historia Roderici, contribuyeron a propagar la voz «Extremo» ${ }^{18}$, que desde 1169 a 1176 aparecen también, como ejemplo único pero importante, en la colección diplomática del monasterio de Oña, es decir, en territorio castellano ${ }^{19}$.

Emplear, pues, en 1181 el término "Extremo" para designar a las tierras leonesas situadas al sur del Duero no significaba desde el punto de vista lingüístico otra cosa que seguir una tradición viva.

Lo reclamaba la aparición de una realidad territorial nueva, que desde finales de la centuria anterior venía consolidando su personalidad con pasos firmes, y que al no identificarse plenamente con el término Extremadura, como enseguida veremos, hacía necesario un complemento especificador que le diera nombre propio. Así surgen las locuciones «Extrema Dorii» o «Extremaduras del Duero». Entramos con esto en otro aspecto de la cuestión que carece aún de un estudio completo: el de los significados históricos de los distintos términos empleados ${ }^{20}$. Tampoco es este el momento de abordarlo. Me limitaré a hacer algunas observaciones que ayuden a comprender la expresión introducida por los notarios zamoranos. La impresión de que con ella tratan de designar únicamente la parte de las Extremaduras comprendida entre el río Duero y el Sistema Central se halla contrastada por el examen de todos los textos en los

\footnotetext{
16 «Similiter et omnis Extremitas que trans flumen Dorii habitatur...» Chronica, ed. L. Sánchez BLDA, Madrid, 1950, pág. 9.

$17 \mathrm{Ibid}$., págs. 15, 19, 23, 59, Extremo; Extremadura: 28, 84 ss.

${ }^{18}$ Chronica Adefonsi Imperatoris, pág. 177: «Extremi populos», respecto a la Historia Roderici, cfr. la nota 21.

19 "Regnante Aldefonso... in Toleo et in Extremis"; «... in Burgis et in Extremis". L. DEL Alamo, Colección doplomática de San Salvador de Oña (822-1284). I. Madrid, 1950, págs. 281, 294, 299, 300 y 306.

${ }_{20}$ Existen indicaciones, aunque suficientes, en diversos autores. Véase, además del trabajo varias veces citado de G. MARTínez DíEz, el de L.M. VILLAR GARCIA, La Extremadura castellano-leonesa. Guerreros, clérigos y campesinos (711-1252) Valladolid, 1986, págs. 2139.
} 
que aparece. Este mismo sentido tiene en la historiografía posterior, sobretodo en la del siglo xVI, como enseguida veremos. En cuanto a la necesidad de un nombre propio que la individualizara, que hemos justificado en primer lugar por el desarrollo de su personalidad, hay que mencionar también la existencia de otros factores, acuciantes de la misma, tales como la presencia de otros territorios dentro del vasto espacio de las Extremaduras, que no se identificaban con los «Extremos del Duero", alguno de los cuales, como la «Trasierra». empezaba, a su vez, a recibir este apelativo como diferenciador del resto de las Extremaduras. Queremos sobre todo resaltar aquí la existencia en territorio castellano de una Extremadura cisduriense, situada al norte del río Duero. $Y$ no me refiero al espolón soriano, de conquista y repoblación relativamente tardías, sino a la que debemos acostumbrarnos a considerar como la primera Extremadura Castellana, en torno a la cual surgirá incluso el nombre de Extremadura, según se desprende de los documentos aportados por Martínez Díez. Se hallaba situada entre los ríos Duero y Arlanza, en una latitud que iba aproximadamente desde Roa a Osma, y a la que una serie de textos desde época muy remota atribuyen los calificativos de "extremo" y "extremadura" de forma cada vez más concreta, hasta convertirlos prácticamente en nombre propio de la región ${ }^{21}$. Nos ocuparemos en otro lugar también de esta Extremadura cisduriense y de las posibles razones históricas que impulsaron a diferenciarla de la "Castella Vetula". Por ahora bástenos recordar que esta Extemadura, que en la documentación administrativa castellana posterior estará siempre presente, contribuía a su vez a complicar el panorama geográfico del mundo de las Extremaduras.

${ }^{21}$ Los testimonios empiezan con expresiones genéricas de las crónicas altomedievales, en las que se habla de "extremis Castellae", "extremi fines provinciae», aplicados a estas y otras tierras exteriores de Castilla. Reflejo de ellas, aunque ya aplicadas a la zona que nos ocupa son las que aparecen tardiamente en la Historia roderici («Langa, quae est in extremis locis», «pervenit ad extremas partes iuxta alveum qui dicitur Dorio». R. MENENDEZ PIDAL, La España del Cid, II, págs. 333y 934), que demuestran la continuidad en la aplicación de tal designación a esa zona. Entre medias hay otras en las que los términos Extremo y Extremadura parecen tener ya el carácter de nombre propio de la misma: «Santo Stefano de Extremo»: documento de 1068 publicado por L. SeRRANo, Colección diplomática de San Salvador del Moral. Valladolid, 1906, pág. 6; «In Frescinosa, in Extrematura..., in alcopa de Covos in Extramatura". A. UBiero ARTETA, Cartulario de San Millán de la Cogolla (7591076). Valencia, 1976, pág. 347. Citados por G. MARTínez diez, Origen del nombre, pág. 16. En fecha imprecisa, pero no muy distante de éstas, los anales castellanos mencionan a Gormaz, Osma y San Esteban como lugares de Extremaduta: «/ era MLVII dederunt sarraceni falifa ad Sanciun Garciam comiten suas casas, id est, Gormaz, Osma et Sanctum Stephanum et alias casas in Extremadura". M. GómEZ-Moreno MARTínez, Anales Castellanos. Discurso de ingreso en la Real Academia de la Historia. Madrid, 1917, pág. 26. Cit. por G. Martínez, Origen del nombre, pág. 19. 
Ahora podemos ya comprender porque la expresión «Extremos del Duero" nace en el reino de León y no en Castilla. En ambos casos se vivía la cotidianeidad del gran río meseteño como línea divisoria, como principio de un nuevo espacio geográfico. Pero mientras que para los notarios zamoranos la identificación de ese nuevo espacio con las Extremaduras era un hecho, y por tanto, no quería esfuerzo mental alguno, ya que la Extremadura leonesa empezaba nada más cruzar el río, para los castellanos resultaba imposible hasta tanto que la personalidad de la zona transduriense estuviera no sólo consolidada de hecho sino además percibida y aceptada conceptualmente como algo distinto de la Extremadura cisduriense. Sólo a partir de ese momento la expresión «Extremos del Duero « dejaría de ser confusa para ellos. Por eso en el siglo XII sólo hablan de Extremo", sin especificaciones. Mientras que más tarde Jiménez de Prada puede utilizar ya la expresión completa.

\section{HUMANISMO Y EDAD MODERNA}

La historiografía medieval posterior a Alfonso el Sabio apenas tiene interés para el tema que nos ocupa. Hay que esperar al despertar renacentista para que el problema se replantee de nuevo, impulsado por las corrientes intelectuales del humanismo y por las realidades políticas y regionales que enconces se producen. Entre estos factores nuevos citaremos, como más significativos, la generalización de la trashumancia, que se designa en el lenguaje bajomedieval con la expresión de «ir a extremo»; la detención definitiva de la expansión de la palabra «Extremadura" al tropezar con territorios con nombre propio ("reino de Toledo" primero, y después y sobretodo "Andalucía»), siendo sustituída en lo que tenía de específico por el más concreto de «frontera»; y finalmente, el abandono del nombre "Extremadura" en Castilla la Vieja y Castilla la nueva, y la subsiguiente apropiación del mismo por la Extremadura actual, hecho que, en mi opinión, sólo se produce muy a finales del siglo $\mathrm{XV}^{22}$. La presencia de las corrientes humanistas en la historiografía

22 B. Palacios Martín: Origen de la conciencia regional extremeña: el nombre y el concepto de Extremadura. "Alcántara", 13-14 (1988), págs. 14-18; ID. Extremadura en la época de Hernán Cortés. Hacia la formación de la regionalidad extremeña en Hernán Cortés y su tiempo. Actas del congreso "Hernán Cortés y su tiempo. V Centenario (14851985). Mérida Editora Regional de Extremadura, II, 1987, 593-596. Debo denunciar aquí la 
se acusa también desde la segunda mitad de esa centuria, destacando unas veces para bien otras para mal, las aportaciones de Marineo Sículo y Annio de Viterbo, que fijaron una serie de líneas en la temática y en su tratamiento. La euforia política de la España de los Reyes Católicos, Carlos $V$ y aún Felipe II, repercutió sobre el tratamiento de la historia de España en general y de algunos temas en particular. En lo que al nuestro se refiere, debemos resaltar el interés por el género corográfico, que entrañaba la descripción histórico-geográfica de los diferentes paises y regiones. La unidad nacional, que polariza todos los planteamientos historiográficos de esta época, no es óbice para que cada una de esas parte del territorio español sea historiada individualmente dentro del conjunto ${ }^{23}$.

Se considera a Florián de Ocampo como el punto de partida de esta nueva etapa historiográfica, propiamente española, a causa del rigor científico y la calidad formal que imprime a su trabajo. El va a retomar también la cuestión del nombre de Extremadura y su significación histórica y etimológica. $Y$ aunque su opinión no va a ser comúnmente aceptada, se observa que en el modo de plantearla será unánimemente tomado como punto de referencia por quienes escriben después de él, cualquiera que sea la solución que le den. Ocampo se esfuerza por conjugar la etimología de Extremaduta con las realidades históricas que ha significado. Es consciente de que el uso que se hace en su época del término no refleja todo su contenido histórico, al haberse abandonado su empleo al norte del Sistema Central ${ }^{24}$. Acaso por esa razón trata de destacar que la Extremadura, entendida como zona limítrofe del reino castellano leonés, tuvo sucesivamente sus lí-

pésima edición de estas actas, hechas por la mencionada Editora, que prescindió del comité científico del congreso para ordenar el material, y de los autores para corregir pruebas. El resultado es, entre otras cosas, el desorden total con el que se presentan ponencias y comunicaciones, que dificulta el seguimiento de las grandes líneas temáticas del congreso, asi como las innumerables erratas que disminuyen el rigor científico de los trabajos y descalifican la edición.

${ }^{23}$ "La unidad política nacional se hace compatible con la autonomía de los antiguos reinos, y el pasado de cada uno, aún en lo posterior a su absorción en la nueva España, es historiado independientemente". B. SÁNCHEZ AlONSO, Historia de la historiografía española. ensayo de un examen de conjunto II. De Ocampo a Solís (1543-1648). Madrid, 1944, pág. 2.

${ }^{24}$ Reflejo de la preocupación entre los niveles más cultos por ese olvido son algunos aforismos recogidos por J. SORAPAN DE RIEROS, Medicina española, contenida en proverbios vulgares de nuestra lengua... Granada, 1616: "Anda, mozo anda / de Burgos a Aranda /. Que de Aranda a Extremadura / yo te llevaré en mi mula». Los cita A. RodRiguez Moñino, Dictados tópicos de Extremadura. Badajoz, 1931, págs. 93-94. 
mites primero en la cresta de la Cordillera Central y luego en la cuenca del Guadiana. Esos serían los dos extremos historicos consecutivos, por cuya causa la tierra respectiva "fue dicha Extremadura» ${ }^{25}$. Extremadura, por tanto, deriva de extremo, pero sin ninguna relación con el río Duero, sino con la Sierra y el Guadiana.

Así pues entramos en la historiografía moderna con un perfecto rechazo de la etimología duriense, debido además a un zamorano, del que es dificil suponer que ignorase la denominación «Extrema Dorii» utilizada tres siglos antes en crónicas y documentos. Pero antes de entrar a analizar las reacciones que la postura de Ocampo provoca se hace preciso señalar otras posturas que, coincidiendo con él en rechazar la etimología duriense, lo hacen por otras razones. Son estas las que tratan de desentrañar el sentido etimológico de la palabra «Extremadura» a partir del ultimo de sus significados históricos, el que la identifica con la Extremadura actual. Hoy sabemos muy bien que la palabra llegó a esta región ya hecha, con una larga historia tras de sí. Sobraban, por tanto todas estas elucubraciones. Pero en el siglo XVI, en cambio, el calor despertado por la afloración de la conciencia regional extremeña empujó a los intelectuales a buscarle una etimología autóctona, que reflejará el nuevo significado del término ${ }^{26}$. La primera que conocemos es la del andaluz Pedro de Medina que, conocedor del extraordinario fenomeno de la trashumancia, que de forma tan directa tocaba a Extremadura, pensó que esta palabra derivaba de "extremo" en su segunda acepción fundamental, es decir, entendida como «lugar de pastos»: «Esta provincia se llama Extremadura porque viene a ella a extremo muy gran parte de los ganados de Castilla por los grandes y fértiles dehesas...” ${ }^{27}$. Pensando también en su patria chica, hacia 1572 escribía Pedro Barrantes su impresión de que tal nombre derivaba de extrema-hora, por lo tardío de su reconquista ${ }^{28}$.

${ }^{25}$ «... aquellas sierras en cuyas faldas le (sic) está, mucho tiempo la raya desde reino de León, que lo cortaban en la parte de mediodía, sin que passase más adelante, hasta que tales cumbres tocan por aquel través en la raya de Portugal. Estuvieron aquellos años mucho tiempo puestos como estremo y baluarte final antre moros y cristianos de aquella tierra, por cuya causa mucha tierra de la provincia que después dellos se seguía fue dicha Extremadura". Los quatro libros primeros de la Crónica General de España que recopila el maestro Florián de Campo, criado y cronista del Emperador rey nuestro señor. Zamora, 1543, fol. 17.

${ }^{26}$ B. PALACIOS, Origen de la conciencia regional extremeña..., pág. 20; ID, Extremadura en la época de Hernán Cortés, pág. 596 ss.

${ }_{27}$ P. DE MEDINA: Libro de las grandezas y cosas memorables de España. (Sevilla, 1548). Ed. BAE.

${ }^{28}$ P. BARRANTES: Historia y antigüedades de la villa de Alcántara. Bibl. Nac. de Madrid, ms. 17.996. Lo cita VICENTE BARRANTES, Aparato bibliográfico para la historia de Extremadura, I. Madrid, 1875, p. 177. 
Desde entonces se producirá en la historiografía extremeña un equívoco permanente en torno al significado del nombre de Extremadura, al no distinguirse sus raíces histórico-lingüísticas de sus últimos significados. Para no abundar demasiado en este tema, que he tratado ya en otros lugares, me limitaré a ofrecer este significativo texto de Sorapán de Rieros: «Dizen algunos que se le impuso a esta provincia el nombre de Extremadura por ser de invierno frigidísima y en el estío muy cálida: pero la experiencia nos muestra lo contrario, y así no se admite esta razón. El maestro Pedro de Medina, en el Libro de las grandezas de España, afirma que tiene este nombre porque baja el ganado de Castilla a estremo, a Extremadura. Pero la razón que más cuadra y que se ha de tener por verdadera, trae el P. Mariana en el libro 9 de la Crónica de España, donde dize que el nombre de Extremadura es un compuesto de estremo y de durio, como si dixessemos los estremos del río Duero: porque llegaban los estremos de aquella provincia y reino de Duero hasta todo lo que ahora se dize Extremadura» ${ }^{29}$.

Sorapán no supera, sino que incrementa, el afán de mezclar el significado etimológico de la palabra con sus significados históricos. Pero vuelve a universalizar el problema sacándolo de los planteamientos restrictivos de sus coterráneos. Y además formula taxativamente la teoría de su derivación de los "extremos del Duero", atribuyendosela al P. Mariana. Pero ¿Fueron realmente así las cosas?. Un repaso de la historiografía que siguió a Ocampo y Medina nos demuestra lo contrario. No sólo no es Mariana el que formula esa teoría, sino que incluso muestra cierta resistencia a aceptarla, como veremos. Que nosotros sepamos, aparece con anterioridad en otros autores como Zurita (1562), Garibay (1571) y Morales (1586). De ellos, lo más explícitos son Morales y Garibay, que sin duda contribuyeron más que nadie a su divulgación, aunque amparándose (el segundo) en la autoridad de Zurita. En efecto, Esteban de Garibay, en un ataque frontal a la tesis de Ocampo, afirma: "Cuya denominación, tratando de esta misma materia, puesto caso que Florián de Campo dize que fue por haber sido estas montañas estremo y baluarte entre los christianos y moros de aquellas partes y que por eso se dixo Estremadura, tengo yo en esto por mejor y más firme opinión haberse dicho por ser estre-

${ }^{29}$ J. de Sorapan de Rieros, Medicina española, págs. 242-243. 
mos de Duero, como lo nota Hierónymo Çurita» ${ }^{30}$. Lo que realmente hemos encontrado en Jerónimo Zurita es una postura más sutil de lo que podía hacernos pensar la atribución de Garibay, si bien éste no carece de fundamento. En efecto, siguiento los pasos de Annio de Viterbo y de cuantos después trataron estos mismo temas, Zurita menciona una serie de ríos españoles considerados origen de topónimos: de Ibero o Ebro, Iberia; del Betis, la Bética, etc., añadiendo a continuación: "Y en los tiempos que estaban aún los moros apoderados de la mayor parte de España llamaron a las regiones vecinas al río Duero, Extremaduras" ${ }^{31}$.

Con este material en las manos, Juan de Mariana, en su Historia General de España, publicada por primera vez en 1601, adopta al principio una actitud ecléctica dudando entre la postura de Ocampo y la de los autores antes mecionados, pero al final se decantará por estos últimos. Así al comienzo de su obra escribe de «Extremadura, así dicha por haber, después que se comenzó a recobrar España de los moros con varios sucesos de guerra, sido mucho tiempo frontera y lo extremo y postrero que por aquella parte poseian los cristianos. Otrosí traen diferente derivación y causa deste nombre de Extremadura, cuya opinión se relatará en otro lugar y en éste ni la reprobamos ni la recibimos". En efecto, más adelante, sin mencionar la opinión contraria de Ocampo, se apunta como de pasada a la etimología duriense: «... y pasado el río Duero, que por largo tiempo fue frontera entre las dos naciones, de que se dijo aquella parte Extremadura, apellido que adelante se trasladó y transfirió a otra comarca, si bien está lejos del río Duero, del cual al principio se forjó el nombre de Extremadura» ${ }^{32}$.

Con estas bendiciones - Zurita, Garibay, Morales, Mariana- la etimología duriense fue fácilmente aceptada por todos los autores cultos que los siguieron, practicamente sin excepción. Correas, Sandoval, Sorapán, Colmenares, Flórez y otros se adhieren a ella más o menos explicitamente. $Y$ ya en la época actual lo han hecho autores como Sánchez

${ }^{30}$ E. DE GaRIBAY: Los quarenta libros del Compendio historial de las chronicas universal y de España, lib. IX, cap. I Barcelona, 1628, fol. 328v «...como saben todos, se llamaban entonces Extrema Dorii, y en castellano Extremadura». A. DE MORALES: Los cinco libros posteriores de la Crónica General de España que continúa... Córdoba, 1586, fol. 148 r.-v.

31 J. ZuRita: Anales de la Corona de Aragón, Lib. I, cap. XIV. ed. A. Canellas, I, Zaragoza, 1976.

${ }^{32}$ J. DE MariAna: Historia General de España. BAE, vol. 30-31. I. Madrid, págs. 5 y 234 respectivamente. 
Albornoz, Floriano y Julio González, por citar sólo algunos nombres significativos ${ }^{33}$. Hasta la publicación del trabajo de G. Martínez Díez, la única contestación que había tenido la etimología duriense provenía, pues, de autores de la Extremadura actual, obsesionados en buscar la definición conceptual de ésta a traves de la interpretación etimológica del nombre. Los resultados de tan disparatada empresa pueden imaginarse. Unicamente Paredes Guillén, a finales del siglo pasado, retomando la interpretación de Pedro de Medina, halló una especie de refugio en la última acepción que tuvo el término "extremo", equivalente a "pastos de invierno", que cuadraba bien a la Extremaduta actual, destino, como se sabe, de los ganados trashumantes, aunque yerra al situar esa acepción como origen del nombre: “Extremadura» viene de «Extremos», y no del nombre del río Duero: que esta voz vale tanto como invernadero; y que se llamaban Extremaduras las comarcas que comprendían los extremos de los viajes que hacían los rebaños desde los agostaderos a los invernaderos" ${ }^{34}$. Por otra parte, ya hemos dicho en otro lugar que, si bien el fenómeno de la trashumancia pudo influir e influyó sin duda en la apropiación del nombre por la Extremadura actual, sin embargo, de ninguna manera está presente en la formación del término, muy anterior en su origen, como es de sobra conocido. De manera que todas las objecciones hechas a la etimología duriense por esa vía, caen en el vacío.

Los trabajos recientes de G. Martínez Díez vuelven a desenterrar el hacha de guerra contra élla, bien que sobre unos argumentos históricos y, al parecer también lingüisticos, muy diferentes. Lo que, en mi opinión, no se podrá hacer ya es atribuir la etimología duriense a los notarios zamoranos. Estos popularizaron la denominación «Extremos del Duero» como específica de las Extremaduras situadas entre ese río y la Cordillera Central. Pero nada permite suponer que tuvieran ninguna intención de interpretar el nombre de Extremadura como derivado de «extremo» y de «Duero». Fueron los analistas del siglo XVI, a partir de Zurita, quienes, contagiados de los gustos humanistas de ligar a los ríos el nombre de las regiones española, lanzaron esa interpretación etimológica que luego ha sido repetida sistemáticamente hasta nuestros días, con la sola excepción de aquellos que, al limitar la cuestión a la Extremadura actual, par-

\footnotetext{
${ }^{33}$ Véase, por no multiplicar las citas, A. Floriano Cumbreño, Estudios de historia de Cáceres, I. págs. 90-91.

${ }^{34} \mathrm{~V}$. PAREDES GUILLEN: Historia de los foramontanos celtiberos desde 10 más remotos tiempos hasta nuestros dias. Plasencia, 1988. Ver también su obra Origen del nombre de Extremaduta. Plasencia, 1886.
} 
tían de planteamientos erróneos y llegaban a conclusiones equivocadas y casi siempre disparatadas.

Es hora, pues, de que se inicie un estudio crítico de esta cuestión, que no podrá ser sólo de historiadores o lingüistas, sino resultado de la colaboración de ambos. 
